\title{
Graphene oxide nanofibers: a nanocarbon material with tuneable electrochemical
}

\section{properties}

\author{
D. Torres ${ }^{1}$, S. Pérez-Rodríguez, D. Sebastián, J.L. Pinilla, M.J. Lázaro, I. Suelves \\ Instituto de Carboquímica, CSIC, Miguel Luesma Castán 4, 50018 Zaragoza, Spain
}

\begin{abstract}
We report the electrochemical properties of a novel nanocarbon material obtained by chemical oxidation and ultrasound-assisted exfoliation of fishbone carbon nanofibers (CNF). The resulting material maintains its tubular morphology and presents a characteristic interlayer spacing of graphene oxide (above $0.75 \mathrm{~nm}$ ). Thus, this is called graphene oxide nanofibers (GONF). The new rearrangement of the accessible $\mathrm{sp}^{2}$-carbon domains makes the GONF a potential alternative for electrochemical energy conversion/storage applications, showing a developed porosity and tuneable surface chemistry. The influence of the oxidation degree of GONF on its electrochemical behaviour in $0.5 \mathrm{M} \mathrm{H}_{2} \mathrm{SO}_{4}$ is reported. Cyclic voltammetry and electrochemical impedance spectroscopy evidenced a significant increase of the capacitance for GONF, being 4-27 times higher than that obtained for pristine CNF. An optimum in the capacity $\left(49.2 \mathrm{~F} \mathrm{~g}^{-1}\right)$ was obtained using an oxidation ratio $(\mathrm{OR}=$ $\mathrm{KMnO}_{4} / \mathrm{Sample}$ ) of 6 and $60 \mathrm{~min}$ of sonication. The latter is ascribed to the unique structure of this material containing both graphitic and graphene oxide domains. Higher OR or longer sonication times led to a partial loss of graphitic domains and higher contribution of micropores, which worsen the fast ion/electrolyte transport. Additionally, the optimized material exhibited an improved activity for the hydrogen evolution reaction.
\end{abstract}

Key words: graphene oxide nanofibers, fishbone carbon nanofibers, chemical oxidation, capacitance, hydrogen evolution.

\footnotetext{
${ }^{1}$ Corresponding author. E-mail address: dtorres@icb.csic.es (D. Torres).
} 


\section{INTRODUCTION}

To the classic allotropes of carbon, such as graphite or diamond, new forms of the element have been added in the last decades motivated by the award of several Nobel Prizes: in Chemistry for the "discovery of fullerenes" (1996), or in Physics "for groundbreaking experiments regarding the two-dimensional material graphene" (2010). Among them, carbon nanofibers (CNF) are presented as a unidimensional graphitic material, in the form of nanofilaments, in which the graphene layers are stacked with a not perfectly cylindrical shape, which differentiates them from the multi-wall carbon nanotubes (MWCNT) shown in society by Radushkevich and Lukyanovich already in 1952 [1]. Along with this difference in the stacking, the number of layers is also essential, since a carbon nanofiber of only one layer is not conceivable except in helix-spiral CNF [2], as in the case of single-wall carbon nanotubes (SWCNT). In addition, graphite stacks with a zero angle with respect to the longitudinal growth axis (as in the case of nanotubes) are characteristics in the so-called "ribbon" carbon nanofibers, while nanofibers with graphenes at a non-zero angle and $90^{\circ}$ are known as "fishbone" and "platelet" carbon nanofibers, respectively [3].

CNF have been widely used in catalysis due to the combination of an electrically-conductive, thermoresistant and chemically modifiable structure and a good specific surface area or a low mass density. The aforementioned properties make CNF suitable for a variety of applications, including electrochemical energy conversion and storage, catalysis, electronic devices, sensors or composites both as structural reinforcement and filler to impart electrical conductivity [4-7]. In the field of catalysis, improved performance has been reported using $\mathrm{CNF}$ as support instead of other conventional carbons, such as coke, graphite, activated carbon or carbon black [4]. Promising results have also been obtained for electrocatalytic applications, for example in low temperature fuel cells [8-11]. The latter is ascribed to the developed mesoporosity of CNF which provide adequate mass transport, as well as a good 
dispersion of the active phase. Additionally, CNF present adequate stability in electrochemical environments and high electrical conductivity due to their graphitic carbon structure. These unique features are of interest for the application of CNF in other energetic applications, including supercapacitors or Li-ion batteries [12, 13]. However, the efficient electrochemical energy-storage requires the presence of micropores for adequate charge accumulation and this is where graphene materials generated a great expectation [14-16]. Graphene, frantically tested on all electrochemical devices [17], is the basic structural unit found in graphite and in other conductive nanostructured carbons as nanotubes or nanofibers, due to the free movement of $\pi$-electrons along its $2 \mathrm{D} \mathrm{sp}{ }^{2}$-carbon network [7, 18]. In addition to its ultrahigh electrical conductivity $\left(10^{5}-10^{6} \mathrm{~S} \mathrm{~m}^{-1}\right)$, graphene exhibits a large theoretical surface area $\left(\sim 2600 \mathrm{~m}^{2} \mathrm{~g}^{-1}\right)$.

As catalytic support, nanostructured carbon materials have been the object of functionalization to improve the surface reactivity towards physisorption/chemisorption of species and their hydrophilicity to be used in aqueous environments or electrolytes. Most of the works published regarding chemical surface oxidation of nanocarbon materials focus on carbon nanofilaments and graphene and the use of strong oxidizing agents [19-21]. However, these treatments may alter the texture, developing even a larger specific surface, and morphology of these materials thus leading to the partial destruction of the initial structure or a significant reduction of the electrical conductivity $[22,23]$. In the case of graphene, the chemical oxidation-reduction method is the most economical for its mass production, and it also facilitates its functionalization and applicability in terms of dispersion and solubility [20]. This approach usually involves the production of graphene oxide (GO) from graphite by following the modified Hummers method [24]. GO precursors consist of oxidized graphene sheets with hydroxyl and epoxide groups disrupting the $\mathrm{sp}^{2}$-conjugated graphene network and carboxylic and carbonyl groups on the edges $[25,26]$. In addition, the presence of sulphur- 
containing groups (mainly organosulfate groups) anchored to the resulting GO obtained thought this method has also been reported [27, 28]. In addition to providing a hydrophilic carbon surface, oxygen and sulphur- functional groups affect the intimate properties of the graphene structure, such as electronic conduction or allocation of edge or quantum confinement effects. On the other hand, these surface functional groups and lattice defects (vacancies, holes) may act as active centres for different reactions or as anchoring sites of metal nanoparticles.

In the present work, a novel material such as GO nanofibers (GONF) is obtained, and the effect of its degree of exfoliation/functionalization on its electrochemical properties is studied. After the use of the modified Hummers method $\left(\mathrm{KMnO}_{4}\right.$ in $\left.\mathrm{H}_{2} \mathrm{SO}_{4}\right)$ and ultrasound-assisted exfoliation, the resulting material combines the one-dimensional morphology of its parent CNF with the existence of accessible graphene oxide sheets, in which the interlayer spacing is doubled (above $0.75 \mathrm{~nm}$ ). These graphene oxide stacks come from those of graphite in the original nanofiber but including the intercalation of oxygenated groups and sulphurcontaining groups from the concentrated sulphuric acid used in the synthesis. The combined micro- and mesoporosity in GONF is expected to provide adequate charge accumulation and fast transport of electrons and reactants. Additionally, the O- and S-groups bonded to the carbon framework play an important role in the hydrophilicity, which is a key factor for electrochemical applications in aqueous media [29]. Likewise, aggregates of nanofilamentshape particles mimic the inverse structure of conventional porous support, being able to prevent any mass transfer limitations [30]. The synthesis of these GONF was published by our research group previously [31] and represents a scalable and high-yield alternative to graphite as starting material for the obtention of graphene-based materials for applications in catalysis, composite materials or energy applications. Here, the oxidation ratio $\left(\mathrm{KMnO}_{4} /\right.$ Sample $=6.0$ and 8.6 , wt. \%) and the time of sonication $(60$ and $120 \mathrm{~min})$ were 
studied in order to assess its effect on the formation of GONF and their properties since both operational parameters have proved to be very influential in the graphite exfoliation efficiency [32-34]. The resultant GONF were studied by cyclic voltammetry and impedance electrochemical spectroscopy in acid media $\left(0.5 \mathrm{M} \mathrm{H}_{2} \mathrm{SO}_{4}\right)$ to determine the capacitance and to evaluate the dynamic processes taking place in the electrode/electrolyte interface. Additionally, the electrochemical activity to the hydrogen evolution reaction (HER) of GONF was also tested. In this context, HER occurs at potentials below $0 \mathrm{~V}$ vs. reversible hydrogen electrode (RHE) in aqueous electrolytes and hence, it is a key reaction in energy-conversion devices. The study of supported catalysts for hydrogen evolution has attracted special attention. However, the performance of carbon electrodes has been rarely studied [35]. In this work, for the first time the electrochemical properties of GONF are studied and related to their physicochemical characterization.

\section{MATERIALS AND METHODS}

\subsection{Fishbone carbon nanofibers synthesis}

CNF were synthetized via catalytic decomposition of biogas (CDB) in a rotary bed reactor elsewhere described [36, 37] but following some updated operating conditions [31]. A $\mathrm{Ni} / \mathrm{Al}_{2} \mathrm{O}_{3}$ catalyst (Ni:Al molar composition: 2:1) prepared by the fusion method [38], was used for carbon nanofibers growth and led to the formation of fishbone carbon nanofibers whose structure is shown in Fig. 1a-b. Raw CNF included metal particles (from the remaining catalyst) as $\mathrm{Ni}$ and $\mathrm{Al}_{2} \mathrm{O}_{3}$ which accounted for $12 \%$ by weight. CNF were obtained in a 180 min run with a feed of $1501 \cdot \mathrm{h}^{-1}$ of $50 \%$ of $\mathrm{CH}_{4}$ and $50 \%$ of $\mathrm{CO}_{2}$ at $600{ }^{\circ} \mathrm{C}$ and with a weight hourly space velocity of $30 \mathrm{l} \cdot \mathrm{g}_{\mathrm{cat}}{ }^{-1} \cdot \mathrm{h}^{-1}$, as described in [31]. Additionally, CNF chemically treated with concentrated $\mathrm{HNO}_{3}(65 \%)$ at room temperature and $2 \mathrm{~h}$ were prepared to remove the Ni content and minimize its possible effect on their electrochemical properties. This material presents a slight oxidation and it is named CNFo for a clear identification. 


\subsection{Obtention and separation of fishbone GONF}

GO suspensions with a mixture of GONF, few-layer graphene oxide flakes (FLGO) and GO quantum dots (GOQD) were obtained using a modified Hummers method [24, 39-41] followed by ultrasonic exfoliation (see scheme in Fig. 1i). In a typical synthesis, $1.5 \mathrm{~g}$ of CNF, $1.5 \mathrm{~g}$ of $\mathrm{NaNO}_{3}$ (purity $\geq 99.0 \%$ ), and $69 \mathrm{ml}$ of $\mathrm{H}_{2} \mathrm{SO}_{4}(96 \%$ ) were stirred together in an ice bath. $\mathrm{KMnO}_{4}$ was slowly added to the mixture under vigorous stirring to obtain the desired ratio of $\mathrm{KMnO}_{4}$ to as prepared CNF according to the optimum oxidation ratio (OR) obtained in a previous work for multiwall carbon nanotubes: $\mathrm{OR}=\mathrm{KMnO}_{4} /$ Sample $=6$ (wt. $\%$; including the catalyst content) [42]. In addition, an OR $=8.6$ is used to study its effect on nanofiber exfoliation. After addition of $\mathrm{KMnO}_{4}$, temperature was kept below $20{ }^{\circ} \mathrm{C}$ during mixing and then the solution was stirred at $30 \pm 5{ }^{\circ} \mathrm{C}$ for 2 hours and at room temperature overnight. After oxidation, a brownish thick paste was formed. Then, $120 \mathrm{ml}$ of deionized water was slowly added while maintaining the temperature below $70{ }^{\circ} \mathrm{C}$. Subsequently, the solution was stirred for $60 \mathrm{~min}$ and was diluted with $300 \mathrm{ml}$ of deionized water. $13 \mathrm{ml}$ of $\mathrm{H}_{2} \mathrm{O}_{2}(33 \%)$ were added dropwise, turning the solution colour to yellowish brown. Resulting material exfoliation was carried out for 60 or 120 minutes in mild sonication. Product was washed by centrifugation with $\mathrm{HCl}(10 \%)$ and deionized water until neutral $\mathrm{pH}$. The clean precipitate was dispersed in deionized water and separated from the rest of products (from FLGO and GOQD) as the precipitate of its centrifugation at $2000 \mathrm{rpm}$. More details about the whole obtention process, including the separation of GOQD and FLGO by differential degressive centrifugation can be found in [31]. Summarizing, treated nanofibers correspond to oxidation under OR of 6.0 and $60 \mathrm{~min}$ of sonication (A), 8.6 and $60 \mathrm{~min}(\mathrm{~B})$ and 8.6 and 120 min (C). Products obtained from the above treatments (GONF, for example) will be indicated hereafter as A-GONF, B-GONF and C-GONF.

\subsection{Physicochemical characterization}


Characterization of all materials was carried out by X-ray diffraction (XRD), transmission electron microscopy (TEM), X-ray photoelectron spectroscopy (XPS) and $\mathrm{N}_{2}$ and $\mathrm{CO}_{2}$ physisorption at $77 \mathrm{~K}$ and $273 \mathrm{~K}$, respectively. As prepared CNF were used without further purification treatment. GONF dispersions were either dried at $60{ }^{\circ} \mathrm{C}$ overnight for powder techniques such as XRD, XPS and $\mathrm{N}_{2}$ physisorption, or directly used for TEM.

XRD patterns of raw CNF, CNFo and dried graphene oxide suspensions were acquired in a Bruker D8 Advance Series 2 diffractometer. The angle range scanned was $3^{\circ}-55^{\circ}$ using a counting step of $0.02^{\circ}$ and a counting time per step of $4 \mathrm{~s}$. XRD data were fitted using the structure analysis software TOPAS (Bruker AXS) including subtraction of a first order Chebyshev polynomial background and peak deconvolution by fitting to pseudo-Voigt curves. The graphite peak fit gave information on structural parameters such as interlayer spacing, $d_{002}$, or mean crystallite size along c axis (transverse to the graphene planes), $L_{c}$, which are used in this study to estimate the exfoliation degree and the average number of graphene layers, $n$, after oxidation method. The mean interlayer spacing was evaluated from the position of the (002) peak applying Bragg's Law [43], while the mean crystallite size was calculated using the Scherrer formula, with a values of $\mathrm{K}=0.89$ [43]. From these, $n$ was calculated as $\left(L_{c} / d_{002}\right)+1[44]$.

The textural properties were measured using a Micromeritics ASAP2020 apparatus for $\mathrm{N}_{2}$ and $\mathrm{CO}_{2}$ physisorption at 77 and $273 \mathrm{~K}$, respectively. The specific surface area $\left(S_{B E T}\right)$ was calculated by the BET method applied to the $\mathrm{N}_{2}$ adsorption isotherm, while the micropore surface area $\left(S_{\text {mic }}\right)$ was obtained by subtraction of the external surface area (obtained by t-plot method) to the $S_{B E T}$. The total pore volume $\left(V_{t}\right)$ was calculated from the $\mathrm{N}_{2}$ adsorbed volume at a relative pressure of $p / p_{0}>0.990$. Density functional theory (DFT) model for $\mathrm{CO}_{2}$ on slitpore carbon was used for the pore size distributions. In addition, $S_{m i c}\left(S_{m i c} C \mathrm{CO}_{2}\right)$ and the 
monolayer capacity of these samples were also calculated using the Dubinin-Radushkevich equation and the $\mathrm{CO}_{2}$ adsorption data.

The surface chemistry was analyzed by XPS. The spectrometer, an ESCAPlus OMICROM equipped with a hemispherical electron energy analyser, was operated at $18.75 \mathrm{kV}$ and $12 \mathrm{~mA}$ $(225 \mathrm{~W})$, using a monochromatic AlK $\alpha$ X-ray source $(h v=1486.7 \mathrm{eV})$ and under vacuum $(<5$ $\times 10^{-9}$ Torr). A survey scan between 1000 and $0 \mathrm{eV}$ was acquired using steps of $0.5 \mathrm{eV}$ and $200 \mathrm{~ms}$ of dwell, while C1s and S2p regions were acquired each $0.1 \mathrm{eV}$ for $500 \mathrm{~ms}$. Analyser pass energies of 50 and $20 \mathrm{eV}$ were used for survey scans and $20 \mathrm{eV}$ for $\mathrm{C} 1 \mathrm{~s}$ and $\mathrm{S} 2 \mathrm{p}$ regions, respectively.

Morphological appearance of CNF and GONF was performed using a Tecnai F30 (FEI) transmission electron microscope, equipped with a cannon of $300 \mathrm{KeV}$ and a maximum resolution of $1.5 \AA$.

\subsection{Electrochemical characterization}

Electrochemical characterization was performed in a conventional three-electrode electrochemical cell. A high surface area carbon rod was used as counter electrode and a reversible hydrogen electrode (RHE) as reference (all potentials in the text are referred to this electrode). The working electrodes were prepared depositing a thin layer of a carbon ink (1 $\mathrm{mg} \mathrm{cm}{ }^{-2}$ ) of the corresponding material on a glassy carbon electrode (geometrical area $=$ $0.385 \mathrm{~cm}^{2}$ ). Inks were prepared by dispersing a known amount of the corresponding carbon material (typically $2 \mathrm{mg}$ ) in a mixture of 50/50 deionized water/isopropyl alcohol 50/50 (v/v) containing 15 wt.\% Nafion® (Sigma Aldrich, 5 wt.\%). An Autolab PGSTAT302 (Metrohm) potentiostat-galvanostat was used to record the electrochemical data. The base electrolyte, 0.5 $\mathrm{M} \mathrm{H}_{2} \mathrm{SO}_{4}$, was saturated with nitrogen previously to each measurement.

Cyclic voltammograms (CV) were obtained cycling the potential from 0.2 to $0.8 \mathrm{~V}$ vs. RHE at different scan rates $\left(5,10,20,50,100\right.$ and $\left.200 \mathrm{mV} \mathrm{s}^{-1}\right)$. The capacitance was determined from 
the integration of the area enclosed by the $\mathrm{CV}$ in all the potential window (where no faradaic process takes place), considering the average value from positive and negative going scans.

Electrochemical impedance spectroscopy (EIS) experiments were carried out using a Frecuency Response Analyzer (FRA) in a frequency range from $100 \mathrm{kHz}$ to $0.01 \mathrm{~Hz}$ with a 10 $\mathrm{mV}$ AC amplitude around three different potentials: 0.2, 0.5 and $0.8 \mathrm{~V}$ vs RHE.

The activity of the carbon materials for the hydrogen evolution reaction (HER) was studied by linear sweep voltammetry (LSV) from 0.5 to $-1.0 \mathrm{~V}$ in the base electrolyte, $0.5 \mathrm{M} \mathrm{H}_{2} \mathrm{SO}_{4}$, using a scan rate of $10 \mathrm{mV} \mathrm{s}^{-1}$.

\section{RESULTS AND DISCUSSION}

\subsection{Effect of the oxidation/sonication treatment on the physicochemical properties of GONF}

Fishbone CNF were subjected to three different oxidation/exfoliation processes in order to obtain GONF with different physicochemical properties. Starting conditions (A treatment) of OR and sonication time are taken according to a previous recent study from our research group on obtaining FLGO from multi-wall carbon nanotubes $(\mathrm{OR}=6$ and $60 \mathrm{~min}$, respectively) [42]. Due to a higher carbon content in the starting CNF using in this work, higher OR (B treatment) and sonication time ( $\mathrm{C}$ treatment) were studied to ensure complete oxygen intercalation of the CNF graphitic layers. In Fig. 1a-b is shown an example of a raw sample of fishbone carbon nanofibers. CNF thus obtained showed a wide diameter distribution around $24-53 \mathrm{~nm}$ and a few microns long and the graphene cones arrangement along the axis at an angle $\alpha$ of $25-35^{\circ}$ due to both the size and shape of the nickel particles (as it is drawn in the image), respectively. These nanofibers are deeply characterized in a previous work where more images can be found [31]. Additionally, Fig. 1 shows TEM images of GONF obtained after A (Fig. 1c-d), B (Fig. 1e-f) and C (Fig. 1g-h) treatments and 2000 
rpm precipitation. In all cases, GONF with higher degree of interlayer spacing than that in the original graphite stacking were obtained, as it will be confirmed by XRD (see below), showing the C-GONF the highest degree of exfoliation. Oxidation promotes the formation of oxygenated groups between the graphene layers of the graphite crystallites in the nanofiber and, presumably, it takes place from the outside towards the inner axis of the nanofibers until the oxidation thereof is complete (as in the case of C-GONF). This process also promotes the total exfoliation and/or the length shortening of the nanofibers, so other materials such as FLGO sheets or GOQD are found, as described in [31], which were separated as supernatant in the $2000 \mathrm{rpm}$ centrifugation stage. A basic scheme of the oxidation/exfoliation of CNF is included in Fig. 1i.

Oxidative treatments promoted the intercalation of oxygenated groups between the graphite arrangement in the CNF as observed in the XRD analysis shown in Fig. 2. As the OR or the sonication time increased, the peak of the (002) graphite plane disappears as expenses of the shifting of the peak at $11.1-11.8^{\circ}$ assigned to the $(002)^{*}$ graphene oxide plane. This process can be monitored considering the $I_{002} / I_{002} *$ ratio (integrated intensities of (002) and $(002) *$ as reference of the transformation degree from the original graphite arrangement towards larger interplanar spacings: $\mathrm{C}$ treatment led to the almost complete oxidation of the graphite domains in the original CNF. The $d$-spacings, $L_{c}$ and the number of layers of the graphite and graphene oxide domains in CNF and the different GONF are listed in Table 1. In this way, the crystalline structure of A- and B-GONF showed the simultaneous presence of the two aforementioned spacings, which evidenced the partial oxidation of the starting carbon nanofibers implying the preservation of their internal axes and, therefore, the filamentous morphology characteristic of GONF. The graphene layers shifting the $d$-spacing from 0.340 $\mathrm{nm}$ in the original $\mathrm{CNF}$ to $0.75-0.79 \mathrm{~nm}$ in the treated materials. Note that the calculated number of layers of the graphite $(002)$ and graphene oxide $(002)^{*}$ domains decreased in all 
GONF as the OR used for their formation increased (from the 20 layers calculated for the original CNF). In the case of C-GONF, the longer exfoliation time (120 min) led to the separation of a greater number of products with low number of graphene layers $(<4)$ that were removed as supernatant in the centrifugation stage, hence their average number of layers $(n=4.5)$ was slightly higher than that observed for the GO domains of B-GONF $(n=4.1)$, obtained under the same OR. C-GONF was considered as GONF due to the residual presence of graphite domains in the nucleus of the nanofiber; however, its filamentous structure collapsed at this point because an excessive exfoliation as TEM images showed. That is, oxidation occurs from outside to inside. The diffractogram of CNFo is also included in Fig. 2 to show the almost complete elimination of nickel with acid conventional treatments (the Ni content is below 1 wt. \%). CNFo nevertheless maintains the original structure of $\mathrm{CNF}$ as reflected in its structural parameters.
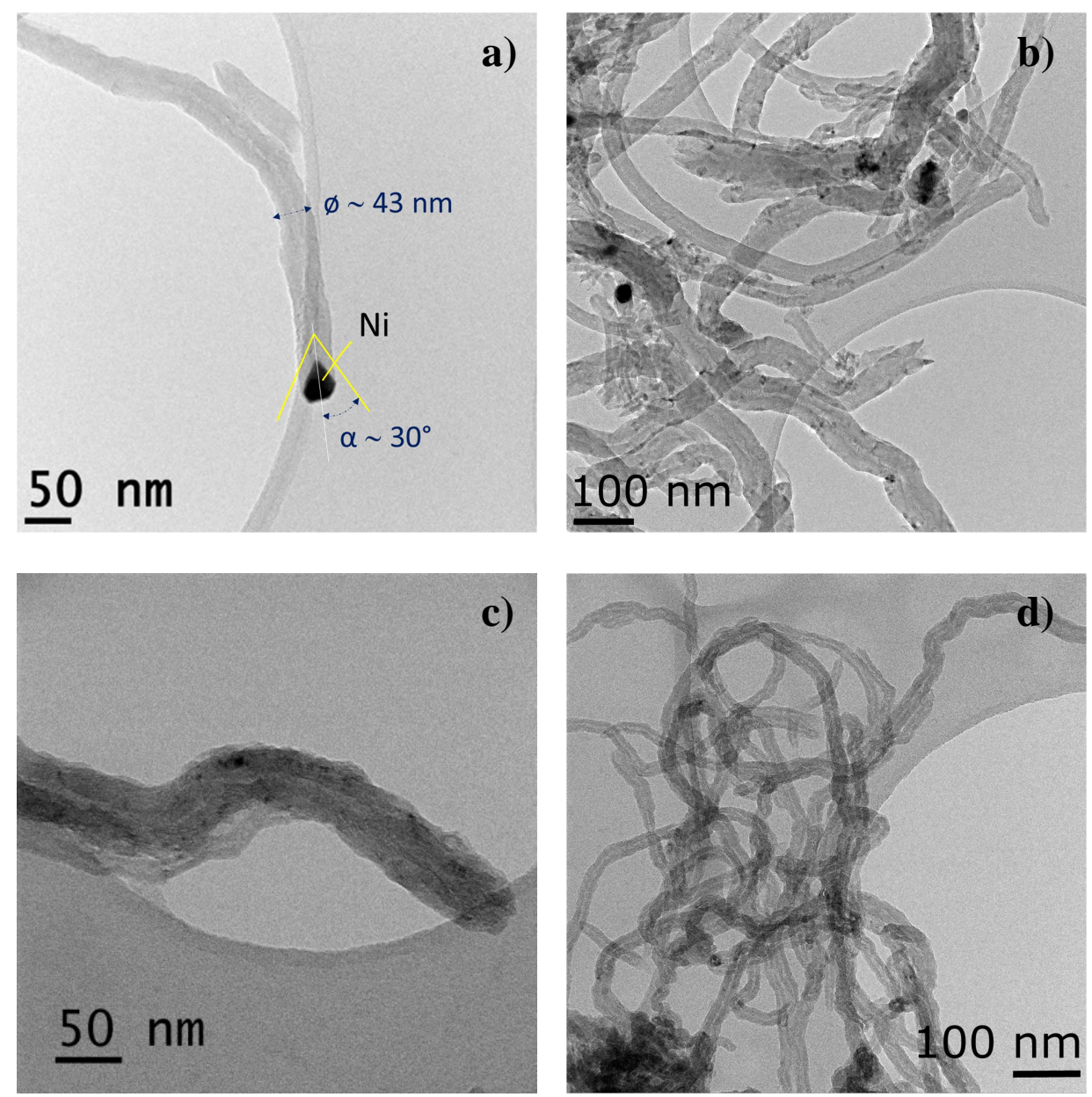

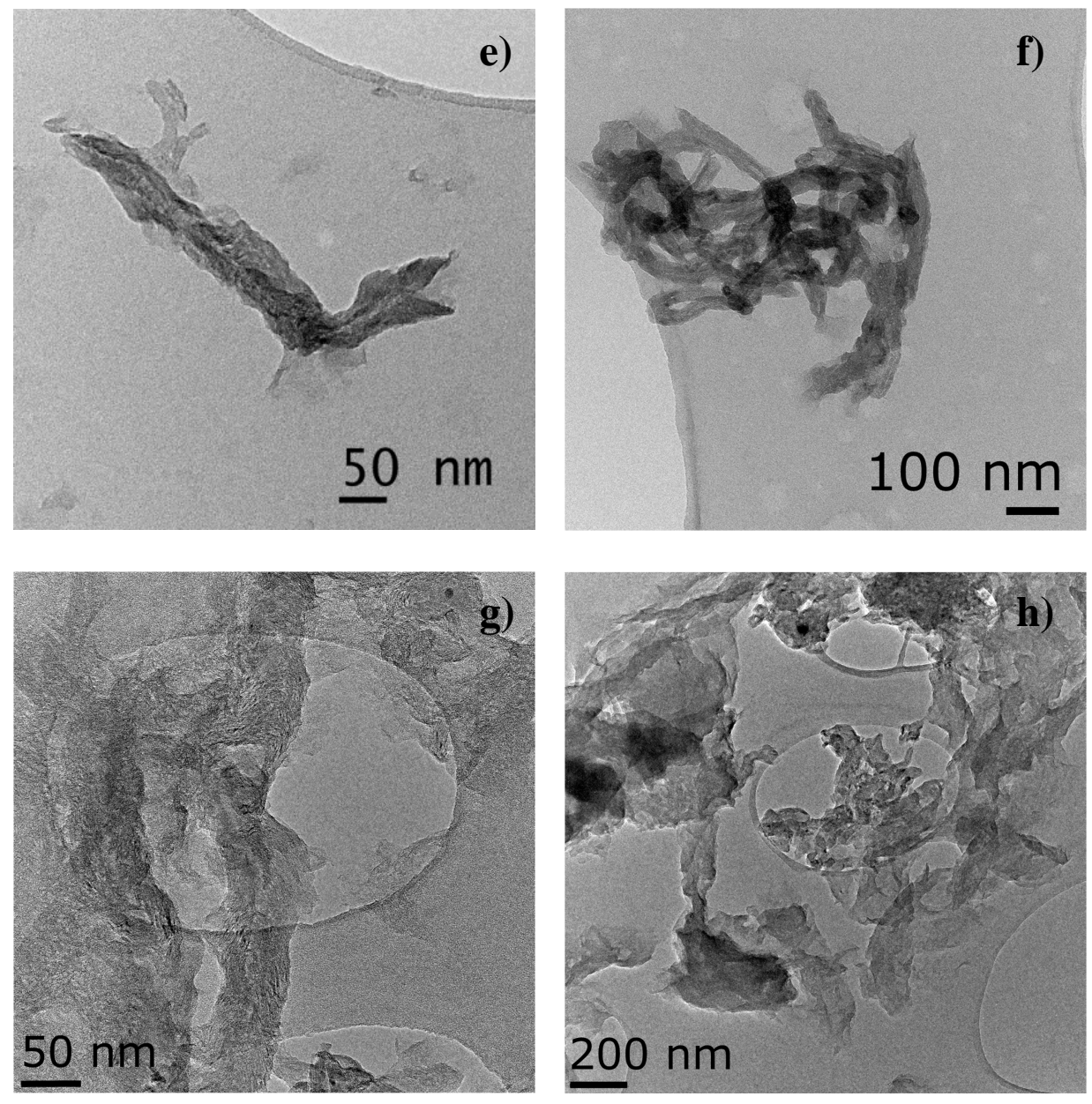

i)

Low Exfoliation

High Exfoliation

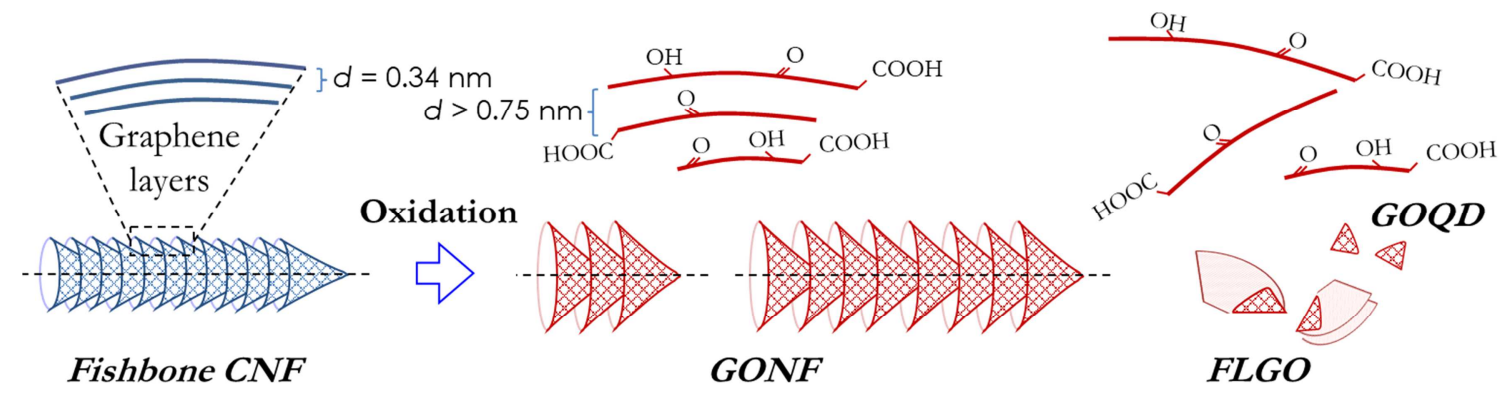

Figure 1. TEM images of (a-b) raw CNF, and $2000 \mathrm{rpm}$ precipitates (mainly GONF) after (cd) A, (e-f) B and (g-h) C treatments. (i) Morphologies and graphene stacking in the graphene oxide-based materials (GONF, FLGO and GOQD) obtained from the oxidation/exfoliation of fishbone CNF. 


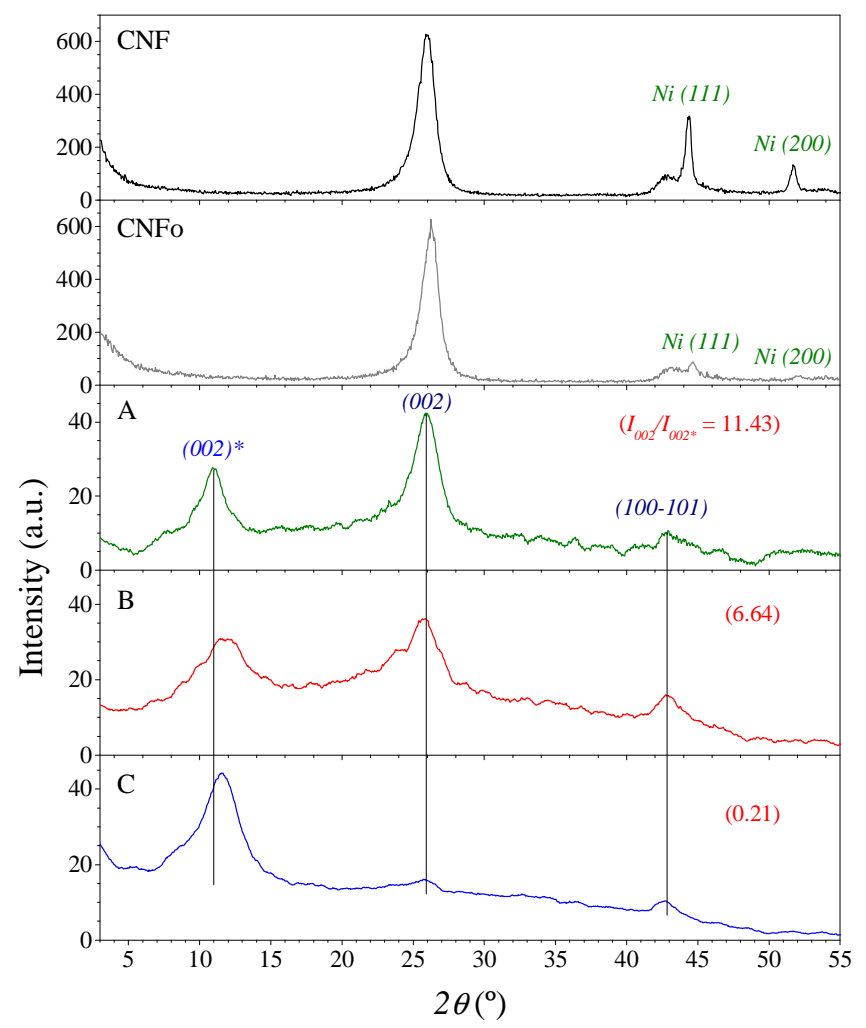

Figure 2. XRD patterns of CNF, CNFo and A-, B- and C-GONF.

Table 1. Structural parameters of CNF, CNFo and FLGO determined by XRD.

\begin{tabular}{|c|c|c|c|c|c|c|}
\hline & \multicolumn{2}{|c|}{$d(\mathrm{~nm})$} & \multicolumn{2}{c|}{$L_{c}(\mathrm{~nm})$} & \multicolumn{2}{c|}{$n$} \\
\hline & $(002)^{*}$ & $(002)$ & $(002)^{*}$ & $(002)$ & $(002)^{*}$ & $(002)$ \\
\hline CNF & - & 0.340 & - & 6.5 & - & 20.0 \\
\hline CNFo & - & 0.339 & - & 6.1 & - & 19.0 \\
\hline A-GONF & 0.793 & 0.342 & 4.7 & 4.2 & 6.9 & 13.2 \\
\hline B-GONF & 0.752 & 0.343 & 2.3 & 2.8 & 4.1 & 9.3 \\
\hline C-GONF & 0.751 & - & 2.6 & - & 4.5 & - \\
\hline
\end{tabular}

The surface composition of CNF and GONF was analyzed by XPS as presented in Fig. 3 and Table 2. Fig. 3a shows the survey spectra of the samples revealing the high increase in the $\mathrm{O}$ content, from 1.9 to $17.9-20.5$ at. \% in CNF and GONF, respectively (Table 2), and the 
apparition of $\mathrm{N}$ and $\mathrm{S}$ after the oxidation/exfoliation treatment. Both $\mathrm{S}$ and $\mathrm{N}$ were found in A-GONF (0.7 and 2.3; at \%) and B-GONF (0.7 and 3.1; at \%) in higher content than in the original CNF (0.0 at. \% in both cases) and C-GONF (0.6 and 0.6; at \%). C/O ratios of GONF were around 3.7-4.4, typical values of GO obtained through the Hummers' method [45]. The conventional method of Ni removal hardly influenced the oxidation of the starting nanofibers; CNFo presented an oxygen content similar to those observed in CNF (the C/O ratio slightly decreases to 38.7). As seen in the diffractograms (Fig. 2), C-GONF shows a lower oxidation degree than B-GONF (C/O ratios of 4.3 and 3.7, respectively) due to the loss of small stacks of graphene oxide sheets by increasing the exfoliation time to $2 \mathrm{~h}$. This phenomenon was also observed for the S content. The Ni (from the CNF growth catalyst) which was observed in the CNF by XRD or TEM, is not detected by XPS because it is mostly embedded in the nanofibers and this is a surface technique (no surface Ni was detected either in CNF or in CNFo). Fig. $3 b$ and $3 c$ show the deconvoluted C1s and S2p high-resolution regions of the samples, respectively. More details about $\mathrm{C} 1 \mathrm{~s}$ or $\mathrm{S} 2 \mathrm{p}$ deconvolutions can be found in our previous works $[15,31]$. Components of the $\mathrm{C} 1 \mathrm{~s}$ regions were fitted using an asymmetric peak at $284.5 \mathrm{eV}$ for $\mathrm{sp}^{2} \quad(\mathrm{C}=\mathrm{C})$ and $\mathrm{sp}^{3}$ hybridized carbon (C-C) [46], and Gaussian/Lorentzian (40:60) for C-O bonds in hydroxyls and epoxides and C-S in sulfonic acid and organosulfates at 286.2-286.6 eV, $\mathrm{C}=\mathrm{O}$ bonds in carbonyls and carboxyls at 288.4-288.7 eV, and the $\pi-\pi^{*}$ shake up satellite, associated with aromatic and unsaturated bonds, at $290.9 \mathrm{eV}$. Oxygen functionalities disrupts the $\mathrm{sp}^{2}$-carbon graphene layers or by inplane groups as hydroxyls and epoxides or by edge groups as carbonyls and carboxyls. According to this, both types will increase as the OR does; however, due to the release of small GO sheets to the suspension, the edge groups $(\mathrm{C}=\mathrm{O}$ in Table 2$)$ are less abundant in the GONF as the sonication time increases. With oxidation, aromaticity and saturation are also lost in the samples, so the contribution of the $\pi-\pi^{*}$ transitions observed by XPS are also lower 
in GONF. The nitric treated nanofibers $(\mathrm{CNFo})$ had very similar participation of oxygen functional groups as the original CNF (see data in Table 2, figure not shown). By deconvolution of the $\mathrm{S} 2 \mathrm{p}$ region (Fig. $3 \mathrm{c})$, the doublets $\left(\mathrm{p}_{3 / 2}\right.$ and $\left.\mathrm{p}_{1 / 2}\right)$ of one or two components were identified: organosulfates $\left(-\mathrm{SO}_{4}\right)$ at $169.1-169.6 \mathrm{eV}\left(\mathrm{p}_{3 / 2}\right)$ bonded to the graphene carbon structure [47], which were detected in all GONF samples, and sulfonic acid $\left(-\mathrm{SO}_{3}{ }^{-}\right)$at $168.1 \mathrm{eV}\left(\mathrm{p}_{3 / 2}\right)$, only detected in C-GONF but in a low percentage $\left(-\mathrm{SO}_{4} /-\mathrm{SO}_{3}{ }^{-}=\right.$ 89/11; at. \%). The highest oxygen content in the case of B-GONF also may come from its participation in the organosulfates groups.

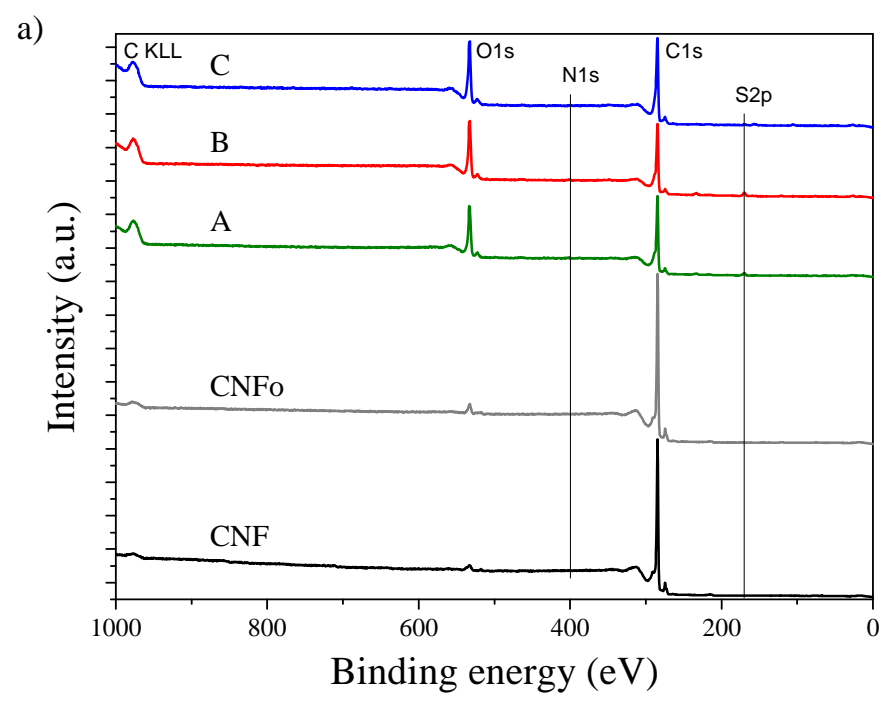



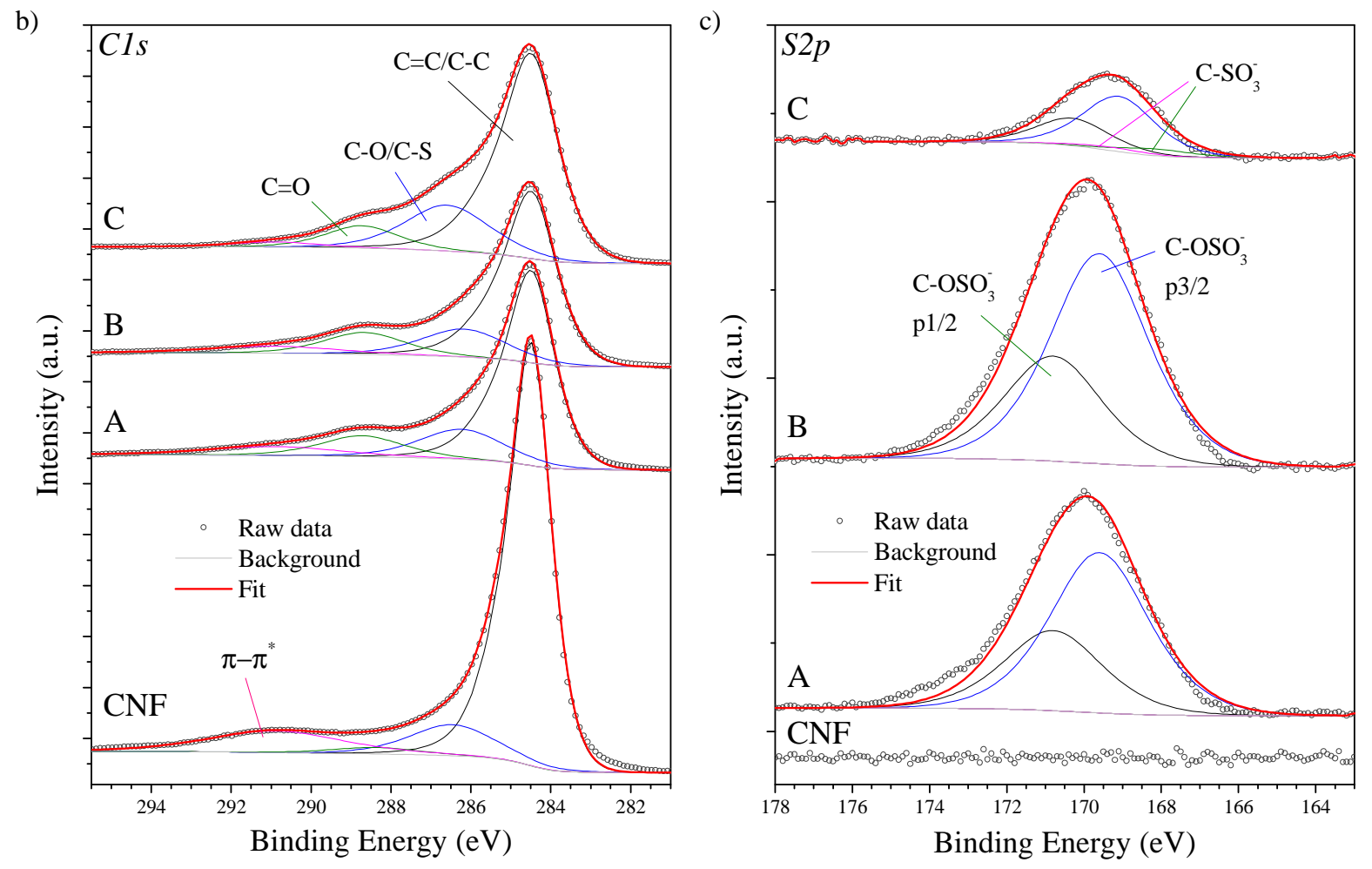

Figure 3. a) XPS Survey; and spectra of the b) C1s and c) S2p regions of CNF and CONF.

CNFo XPS survey spectrum is also included in a).

Table 2. Surface atomic composition (XPS).

\begin{tabular}{|c|c|c|c|c|c|c|c|c|c|c|c|}
\hline & \multicolumn{5}{|c|}{ Survey (at. \%) } & \multicolumn{3}{c|}{ C1s (\%) } & \multicolumn{3}{c|}{ S2p (\%) } \\
\hline & $\mathrm{C}$ & $\mathrm{O}$ & $\mathrm{N}$ & $\mathrm{S}$ & $\mathrm{C} / \mathrm{O}$ & $\mathrm{C} \mathrm{sp}^{2}$ & $\mathrm{C}-\mathrm{O}$ & $\mathrm{C}=\mathrm{O}$ & $\pi-\pi^{*}$ & ${\mathrm{C}-\mathrm{SO}_{3}^{-}}^{-}$ & ${\mathrm{C}-\mathrm{OSO}_{3}}^{-}$ \\
\hline $\mathrm{CNF}$ & 98.1 & 1.9 & 0.0 & 0.0 & 51.8 & 73.5 & 11.4 & 2.4 & 12.7 & 0.0 & 0.0 \\
\hline CNFo & 97.5 & 2.5 & 0.0 & 0.0 & 38.7 & 77.9 & 10.3 & 1.8 & 10.0 & 0.0 & 0.0 \\
\hline A-GONF & 79.2 & 17.9 & 0.7 & 2.3 & 4.4 & 62.3 & 17.5 & 11.9 & 8.3 & 0.0 & 100.0 \\
\hline B-GONF & 75.7 & 20.5 & 0.7 & 3.1 & 3.7 & 62.9 & 17.5 & 13.0 & 6.6 & 0.0 & 100.0 \\
\hline C-GONF & 80.3 & 18.6 & 0.6 & 0.6 & 4.3 & 64.7 & 23.1 & 9.7 & 2.6 & 11.0 & 89.0 \\
\hline
\end{tabular}


Fig. 4a shows the $\mathrm{N}_{2}$ adsorption/desorption isotherms of CNF and GONF (CNFo isotherms are almost identical to those of CNF and are not shown in Fig. 4). Textural parameters are collected in Table 3. Isotherms of treated samples preserve the form observed for the starting CNF (type IV, according to the IUPAC [48]), but with different hysteresis cycles. Depending on the severity of the treatment, hysteresis cycles of type $\mathrm{H} 3$ can be observed for the starting CNF, CNFo and A-GONF, and type H4 for B- and C-GONF. H4 hysteresis type shows an adsorption branch similar to that of $\mathrm{H} 3$ but with a more pronounced adsorption at low $p / p_{0}$ associated with the filling of micropores, which is frequent in isotherms of micro-mesoporous carbons [48]. Therefore, the resulting hysteresis and the significant increase in microporosity $\left(S_{m i c}\right)$ could be attributed to the appearance of accessible cuneiform pores formed by the separation of the graphene stacked cones that form the nanofiber, and which would be responsible for the calculated $d_{002}{ }^{*}$. The BET specific surface areas of treated samples were similar to that of the untreated CNF $\left(90 \mathrm{~m}^{2} \mathrm{~g}^{-1}\right)$, except in the case of sample C-GONF, which was $181 \mathrm{~m}^{2} \mathrm{~g}^{-1}$, in accordance to an entirely oxidized and exfoliated structure, as also observed by XRD. Likewise, after the B and C treatments, the total pore volume was reduced with respect to A-GONF and original CNF $\left(0.24-0.25 \mathrm{~cm}^{3} \mathrm{~g}^{-1}\right)$, most likely due to the loss of mesoporosity associated with the crosslinking of particles, and which would be reduced by a higher compaction of the products obtained. The adsorption and desorption branches of BGONF and C-GONF do not reach equilibrium at low $p / p_{0}$, which was attributed to a diffusional block, possibly due to the high formation of surface $\mathrm{O}$ and $\mathrm{S}$ functional groups. However, the creation of microporosity as the degree of oxidation/exfoliation increases can be clearly seen in Fig. 4b, which shows the micropore size distribution of the samples obtained by $\mathrm{CO}_{2}$ physisorption. BET calculations using $\mathrm{N}_{2}$ adsorption data underestimate the specific surface area of materials with a high microporous contribution. Using $\mathrm{CO}_{2}$ is possible to know the real micropore surface areas of GONF (Smic_CO $\mathrm{CO}_{2}$ ), reaching values as high as 296 
$\mathrm{m}^{2} \mathrm{~g}^{-1}$, and calculate their monolayer capacities. Both parameters increased as the oxidation ratio and the exfoliation time did. Finally, as in the case of structural properties, the textual properties of carbon nanofibers are not affected after the Ni removal by acid treatment (see CNFo textural parameters in Table 3).
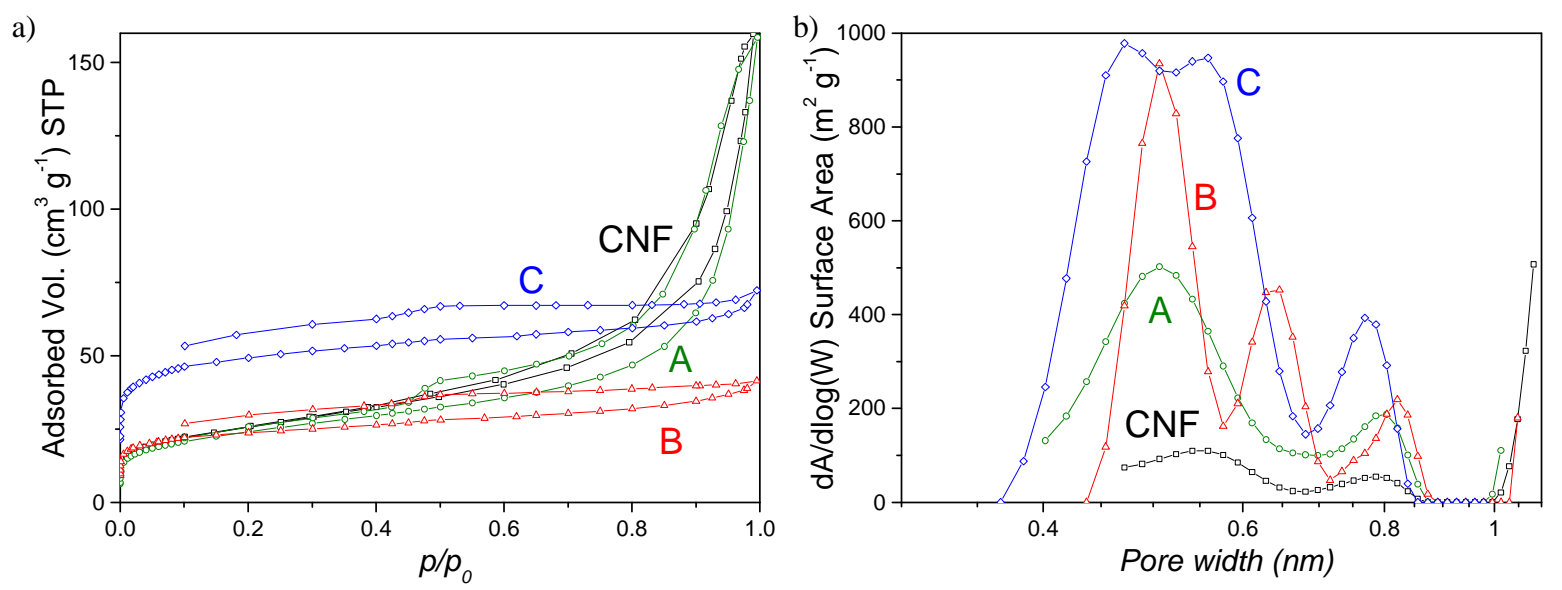

Figure 4. a) Adsorption/desorption isotherms of $\mathrm{N}_{2}$ at $77 \mathrm{~K}$ for $\mathrm{CNF}$ and $\mathrm{A}, \mathrm{B}$ and $\mathrm{C}$ treated samples; b) pore size distribution calculated by $\mathrm{CO}_{2}$ adsorption at $273 \mathrm{~K}$ on $\mathrm{CNF}$ and $\mathrm{A}, \mathrm{B}$ and $\mathrm{C}$ treated samples.

Table 3. Textural parameters of CNF and A, B and C treated CNF.

\begin{tabular}{|c|c|c|c|c|c|}
\hline Sample & $\mathrm{S}_{\mathrm{BET}}{ }^{\mathrm{a}}\left(\mathrm{m}^{2} \mathrm{~g}^{-1}\right)$ & $\mathrm{S}_{\mathrm{mic}}{ }^{\mathrm{b}}\left(\mathrm{m}^{2} \mathrm{~g}^{-1}\right)$ & $\mathrm{V}_{\mathrm{t}}^{\mathrm{c}}\left(\mathrm{cm}^{3} \mathrm{~g}^{-1}\right)$ & $\begin{array}{c}\mathrm{S}_{\mathrm{mic}} \mathrm{CO}_{2}{ }^{\mathrm{d}} \\
\left(\mathrm{m}^{2} \mathrm{~g}^{-1}\right)\end{array}$ & $\begin{array}{c}\text { Monolayer } \\
\text { capacity } \\
\end{array}$ \\
\hline CNF & 90 & 10 & 0.247 & 31 & 6.82 \\
\hline CNFo & 93 & 11 & 0.270 & - & - \\
\hline A-GONF & 85 & 14 & 0.245 & 127 & 27.87 \\
\hline B-GONF & 87 & 52 & 0.064 & 153 & 33.54 \\
\hline C-GONF & 181 & 116 & 0.112 & 296 & 64.70 \\
\hline
\end{tabular}


${ }^{a}$ BET specific surface area. ${ }^{b}$ Micropore surface area by t-plot, $S_{\text {mic }}$ includes pores from 1.7 nm wide. ${ }^{\mathrm{c}}$ Total pore volume at $p / p_{0}=0.990 .{ }^{\mathrm{d}}$ Using the Dubinin-Radushkevich equation, $\mathrm{S}_{\text {mic_- }} \mathrm{CO}_{2}$ includes pores from $0.4 \mathrm{~nm}$ wide.

\subsection{Electrochemical characterization of GONF with different oxidation/exfoliation} degree

$\mathrm{CV}$ were recorded in the base electrolyte $\left(0.5 \mathrm{M} \mathrm{H}_{2} \mathrm{SO}_{4}\right)$ at $5,10,20,50,100$ and $200 \mathrm{mV} \mathrm{s}^{-1}$ for CNF, CNFo and GONF. Fig. 5a shows the CV obtained for A-GONF at the different scan rates. From the current density $(\mathrm{j})$ and the scan rate $(\mathrm{dE} / \mathrm{dt}$, i.e. the variation of potential with time), the specific capacitance was calculated following Equation 1:

$\mathrm{j}\left[\mathrm{A} \mathrm{g}^{-1}\right]=\mathrm{C}\left[\mathrm{F} \mathrm{g}^{-1}\right] \cdot \mathrm{dE} / \mathrm{dt}\left[\mathrm{V} \mathrm{s}^{-1}\right]$

Equation 1

The curves of the specific capacitance for CNF and GONF at $20 \mathrm{mV} \mathrm{s}^{-1}$ are given in Fig. $5 \mathrm{~b}$. All materials exhibit a double-layer capacitive behaviour. In addition, a couple of broad redox peaks are also evident for GONF, which are related to pseudocapacitive Faradaic reactions (reversible oxidation/reduction) of oxygen-functionalities generated during chemical oxidation and ultrasound assisted expansion. Additionally, GONF contains sulphur functionalities (with an S amount from 0.6 to 3.1 at. \% depending on the oxidation conditions) which can also introduce reversible pseudo-sites on the carbon surface [29, 49, 50]. Pristine CNF did not show this pseudocapacitance contribution due to the low amount of oxygenated species at this carbon surface (as evidenced by XPS). In the case of the material subjected only to chemical oxidation with concentrated nitric acid (CNFo), the couple of redox peaks was not as evident as GONF, indicating the lower contribution of oxygen-species active in this potential window. It is worth mentioning that first cycle in the CV of GONF exhibited 
slightly larger current density in the potential window $0.2-0.5 \mathrm{~V}$ vs. RHE in the negative going scan (Figure $\mathrm{S} 1, \mathrm{CV}$ at $5 \mathrm{mV} \mathrm{s}^{-1}$ ). This could be related to partial irreversible reduction of oxygen groups. Upon the first cycle, voltammograms were stable within the potential window investigated.

Interestingly, a substantial increase of the double-layer current was observed for GONF, with values of the specific capacitance substantially higher (from 4 to 27 times higher) than that obtained for pristine CNF (1.8 F g $\mathrm{g}^{-1}$, see Fig. 5c). On one hand, the rise in the capacitance resulted from a larger concentration of oxygen groups that contribute to an increased hydrophilicity as well as to faradaic processes from CO-type groups, as reported by BledaMartínez and coworkers for high surface area activated carbon [51, 52]. These oxygen polar groups are created during the oxidation/sonication treatment of the nanofilaments. On the other hand, sulphur species of GONF can also contribute to this enhanced capacitance in comparison to pristine $\mathrm{CNF}[29,49,50]$. These results clearly indicate that chemical oxidation and subsequent ultrasound assisted expansion is a promising strategy to obtain electrodes with an improved capacitance, which might be potentially applicable in different electrochemical devices, such as supercapacitors, batteries or fuel cells. On the other hand, the highest capacitive value $\left(49.2 \mathrm{~F} \mathrm{~g}^{-1}\right)$ was reached by the GONF synthesized using an OR of 6 and under 60 minutes of sonication (A-GONF). Higher oxidation ratios or longer sonication times resulted in a loss of the capacitance with values of 12.0 and $7.2 \mathrm{~F} \mathrm{~g}^{-1}$ for B-GONF and C-GONF, respectively. This optimum capacitive behaviour seems to be related to the particular structure of this material. In this context, the surface oxygen amount was very similar for the three samples (around 18-20\%, see Table 2), and thus similar capacitances would be expected. On the other hand, a progressive increase of the surface area and micropore content was obtained as the severity of the oxidation/sonication treatment increases (see Table 3). However, the specific capacitance increases following the order: C-GONF < B- 
GONF < A-GONF. Therefore, it seems that the particular structure of A-GONF led to these superior capacitive properties. Indeed, this carbon exhibited a hysteresis cycle type H3 (the same than pristine CNF), while type $\mathrm{H} 4$ was observed for B- and C-GONF. H4 hysteresis (and the significant increase in microporosity) was attributed to the formation of cuneiform pores formed by the separation of the graphene stacked cones that form the nanofiber and hence, responsible of the graphene oxide domain $\left(d_{002}{ }^{*}\right.$, calculated by XRD). A-GONF evidenced the presence of both graphitic and graphene oxide domains, although the last contribution was not as evident as for their analogues (B- and C-GONF). Thus, it seems than the oxidation/exfoliation of $\mathrm{CNF}$ leads to the formation of cuneiform pores (and thus graphene oxide domains), which are accessible for the electrolyte ions. However, severe oxidation conditions ( $\mathrm{OR}>6$ or sonication times $>60$ minutes) results in a massive oxidation extent, generating a higher content of micropores (even ultramicropore) inaccessible by the ions or porosity blockage by the high formation of oxygenated species. In agreement with the latter, B- and C-samples showed an important reduction of the total pore volume.

In contrast, chemical oxidation with nitric acid led to a similar capacitance $\left(1.2 \mathrm{~F} \mathrm{~g}^{-1}\right)$ in comparison to bare CNF. In this context, this treatment led to the removal of nickel impurities but it was weak to generate a high extent of surface oxygen, as showed XPS analysis.

Fig. 5c evidences a similar value of the gravimetric capacitance regardless of the scan rate. However, a slight decrease of the capacitance was observed for B- and C-GONF as potential cycling is faster owing to a diffusion limitation of ions in the electrolyte (Fig. 5d). Interestingly, A-GONF was less vulnerable to capacitive loss, which might be related again to its particular structure with more accessible pores. Thus, we can conclude that A-GONF presents superior capacitive behaviour than their analogues (B- and C-GONF). 

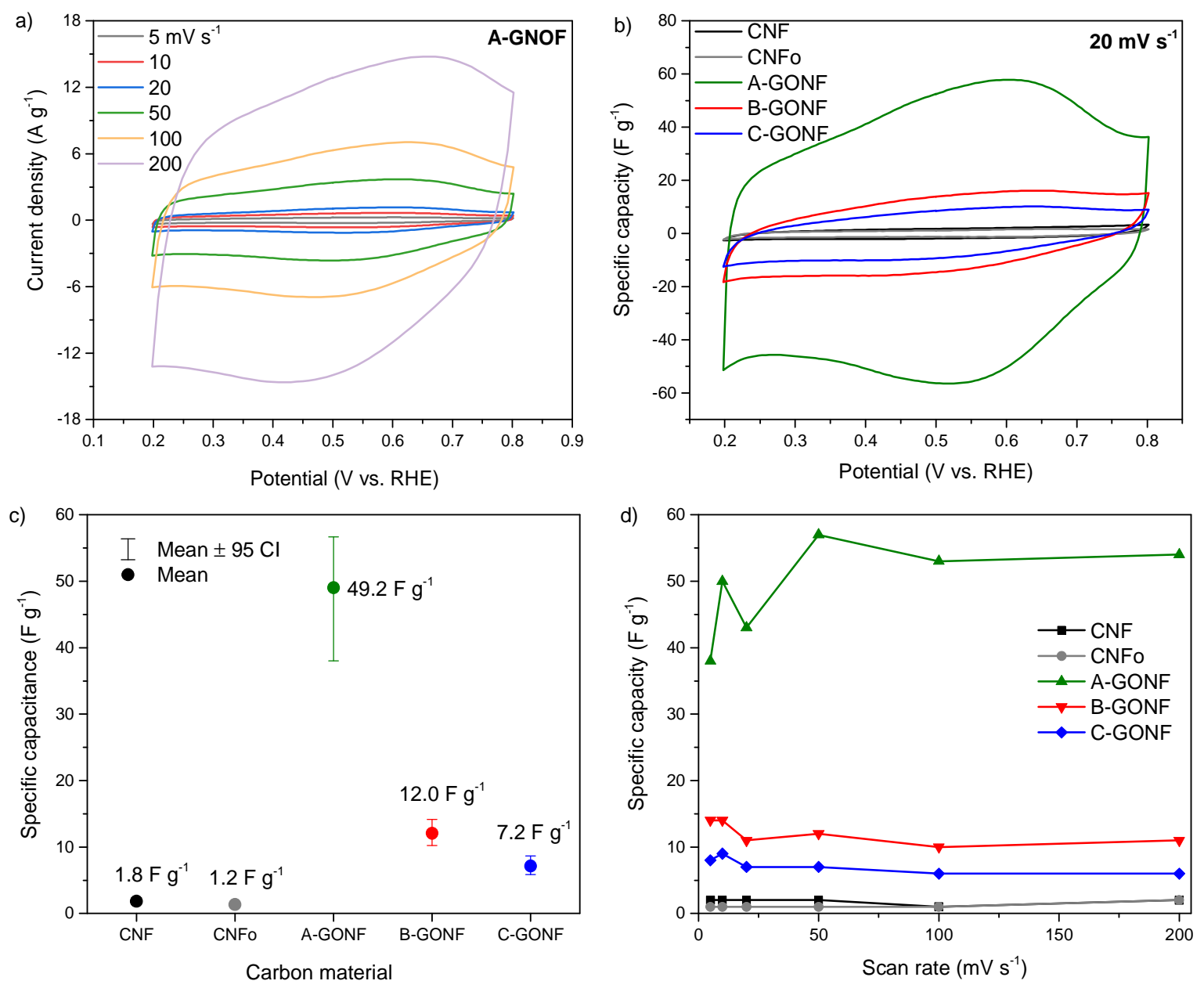

Figure 5. a) CV from 0.2 to $0.8 \mathrm{~V}$ vs. RHE at different scan rates $(5,10,20,50,100$ and 200 $\mathrm{mV} \mathrm{s}^{-1}$ ) of A-GONF. b) Specific capacitance vs. potential curves at $20 \mathrm{mV} \mathrm{s}^{-1}$ for CNF, CNFo, and A, B and C treated samples. c) Deviation and average specific capacitances. d) Specific capacitances as a function of the scan rate. Electrolyte: $0.5 \mathrm{M} \mathrm{H}_{2} \mathrm{SO}_{4}$.

EIS is a powerful tool to differentiate resistive phenomenon associated with electrochemical energy storage. An alternative current of $10 \mathrm{mV}$ amplitude was applied at different potentials $(0.2,0.5$ and $0.8 \mathrm{~V}$ vs. RHE) to study the penetration ability of the electrolyte ions through the porous electrodes at a different frequency. It is important to highlight that double-layer capacitive behaviour is expected at 0.2 and $0.8 \mathrm{~V}$, whereas at $0.2 \mathrm{~V}$ the pseudocapacitive faradaic contribution also occurs by the oxidation/reduction of oxygenates, in agreement with 
the $\mathrm{CV}$ results. Nyquist plots obtained at $0.5 \mathrm{~V}$ are given in Fig. 6a. At frequencies higher than $2 \mathrm{kHz}$, inductive effects were evident in the experimental data due to the presence of parasitic effects. The latter might result in electric wires, capacitor connectors and/or noise. These points above $2 \mathrm{kHz}$ have been removed from the plots. The high frequency intercept at the real axis is attributed to the equivalent cell resistance $\left(R_{s}\right)$, which is originated by the bulk electrolyte resistance and the internal resistance of the electrode. $R_{s}$ is similar for all the materials with values around 1.6-1.9 $\Omega \mathrm{cm}^{-2}$, being B-GONF the carbon with the lowest resistance. The latter is also evident in the Bode-impedance plots when the phase is close to zero (Fig. 6c and Fig. 6d). In the low frequency region, the slope of Nyquist plots corresponds with the diffusion of the electrolyte ions on the surface carbon electrode [53]. A-GONF presented a high slope at low frequencies, indicative of the fast ion transport at this carbon surface, in line with the $\mathrm{CV}$ results. Nyquist plots of the carbon electrodes at different potentials showed a faster ion transfer at $0.5 \mathrm{~V}$ in comparison to those obtained at 0.2 and 0.8 V (Fig. 6b), which may be related to the pseudocapacitive contribution.

Fig. 6c and Fig. 6e show the Bode-impedance and Bode-phase plots, respectively, for all the materials recorded at $0.5 \mathrm{~V}$. Fig. 6e evidences that at a phase angle of $-45^{\circ}$, where the resistive and capacitive behaviour are equal, the capacitive response frequencies $\left(f_{0}\right)$ decreases following the sequence: A-GONF $(1.0 \mathrm{~Hz})>\mathrm{B}-\mathrm{GONF}(5.7 \mathrm{~Hz})>\mathrm{C}-\mathrm{GONF}(6.7 \mathrm{~Hz})>\mathrm{CNFO}$ $(15.0 \mathrm{~Hz})>\mathrm{CNF}(17.4 \mathrm{~Hz})$. These results show that GONF shows a quicker response in 0.5 $\mathrm{M} \mathrm{H}_{2} \mathrm{SO}_{4}$ than those obtained for pristine $\mathrm{CNF}$ or chemically treated with nitric acid $[54,55]$. Additionally, A-GONF presented the fastest response, indicating its improved capacitive behaviour. Regarding the effect of the potential, a quicker response was again found at $0.5 \mathrm{~V}$ than those obtained at 0.2 or $0.8 \mathrm{~V}$ (Fig. $6 \mathrm{f}$ ).

The dependence of the specific capacitance $\left(\mathrm{F} \mathrm{g}^{-1}\right)$ with the frequency are given in Fig. $6 \mathrm{~g}$. Capacitance values were determined using Equation 2: 
$C=-\left(\frac{1}{2 \pi f Z^{\prime \prime}}\right)$

Equation 2

At low frequencies, the obtained capacitances are in line with the results obtained by CV. Impedance measurements showed again the improved capacitive performance of A-GONF. Additionally, different behaviour was found depending on the oxidation conditions. A-GONF showed an increase of the capacitance as the frequency decreases, and then the curve reaches a plateau at the lower frequency range. In contrast, the plateau was not observed for B- and CGONF. The latter could be attributed to a resistive behaviour by difficult access of the electrolyte ions to the micropores [55-57]. Fig. 6h shows an example of the specific capacitance versus the frequency at $0.2,0.5$ and $0.8 \mathrm{~V}$ for A-GONF. Interestingly, the specific capacitances obtained by EIS at $0.2\left(54.4 \mathrm{~F} \mathrm{~g}^{-1}\right)$ and $0.8 \mathrm{~V}\left(40.4 \mathrm{~F} \mathrm{~g}^{-1}\right)$ are very similar to that determined from $\mathrm{CV}$ experiments $\left(49.2 \mathrm{~F} \mathrm{~g}^{-1}\right)$. At $0.5 \mathrm{~V}$ a higher value was obtained $\left(77.2 \mathrm{~F} \mathrm{~g}^{-}\right.$ ${ }^{1}$ ), which may be related to the pseudocapacitive contribution of Faradaic reactions. A similar trend was observed for B- and C-GONF with capacitances of 16.2 and $14.2 \mathrm{~F} \mathrm{~g}^{-1}$ at $0.5 \mathrm{~V}$, respectively, while lower values were obtained at $0.2\left(11.5\right.$ and $\left.11.9 \mathrm{~F} \mathrm{~g}^{-1}\right)$ and $0.5 \mathrm{~V}(8.9$ and $\left.6.8 \mathrm{~F} \mathrm{~g}^{-1}\right)$.
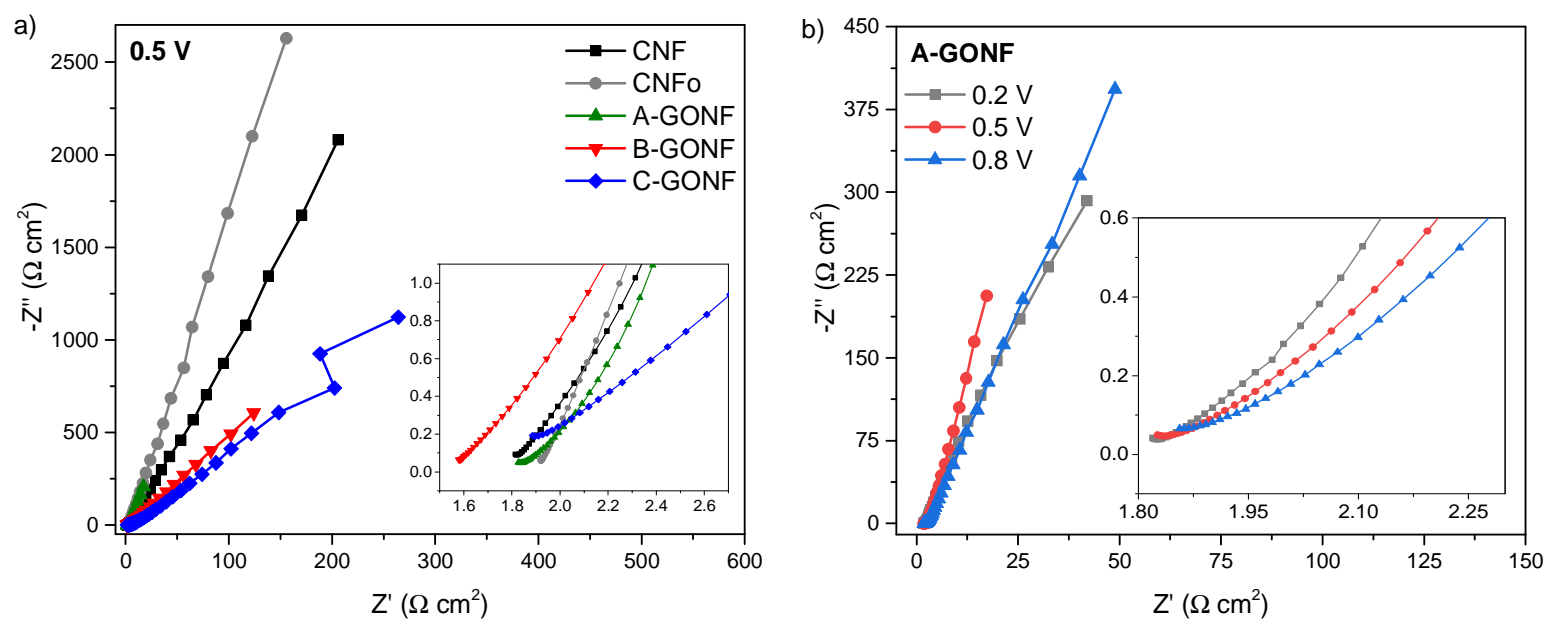

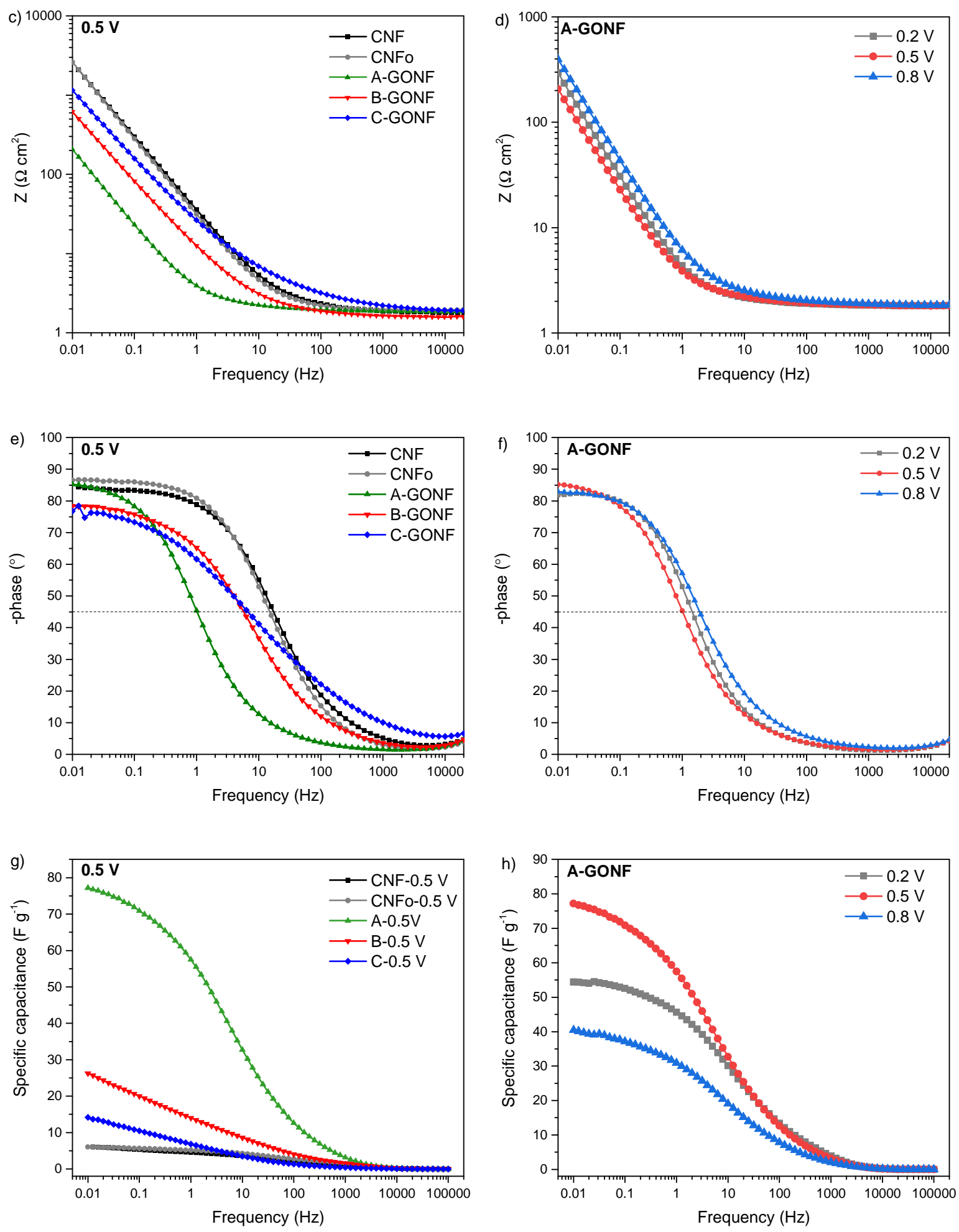

Figure 6. a) Nyquist impedance plots with a $10 \mathrm{mV}$ AC amplitude around $0.5 \mathrm{~V}$ of CNF, $\mathrm{CNF}$, and $\mathrm{A}, \mathrm{B}$ and $\mathrm{C}$ treated samples. b) Influence of the potential in the Nyquist impedance plots for A-GONF. c) Frequency-dependent impedance modulus Bode plots with a $10 \mathrm{mV}$ AC amplitude around $0.5 \mathrm{~V}$. d) Influence of the potential in the frequency-dependent impedance 
modulus plots for A-GONF. e) Frequency-dependent phase angle Bode plots with a $10 \mathrm{mV}$ AC amplitude around $0.5 \mathrm{~V}$. f) Influence of the potential in the frequency-dependent phase angle Bode plots for A-GONF. g) Specific capacitance vs. frequency curves with a $10 \mathrm{mV}$ AC amplitude around $0.5 \mathrm{~V} . \mathrm{h}$ ) Influence of the potential in the specific capacitance vs. frequency curves for A-GONF. Electrolyte: $0.5 \mathrm{M} \mathrm{H}_{2} \mathrm{SO}_{4}$.

Finally, the activity of GONF toward the HER was evaluated. Hydrogen evolution occurs by water reduction in aqueous electrolytes, and hence, it is a key reaction in a variety of electrochemical applications. Indeed, HER is a key step for the production of hydrogen in water electrolysers, but it is also an undesired side reaction in aqueous supercapacitors, metalair and redox flow batteries. Recently, it was found that the introduction of oxygenated species by chemical treatment in nitric acid led to a lower activity toward the HER for the carbon black Vulcan XC-72R [58, 59]. The influence of electrochemical hydrogen storage as a step in the HER process occurring on carbon materials cannot be discarded too [60]. Herein, the influence of chemical oxidation and subsequent ultrasound-assisted expansion of fishbone carbon nanofibers on the activity for hydrogen evolution has been studied. LSV are given in Fig. 7 for CNF and GONF. 


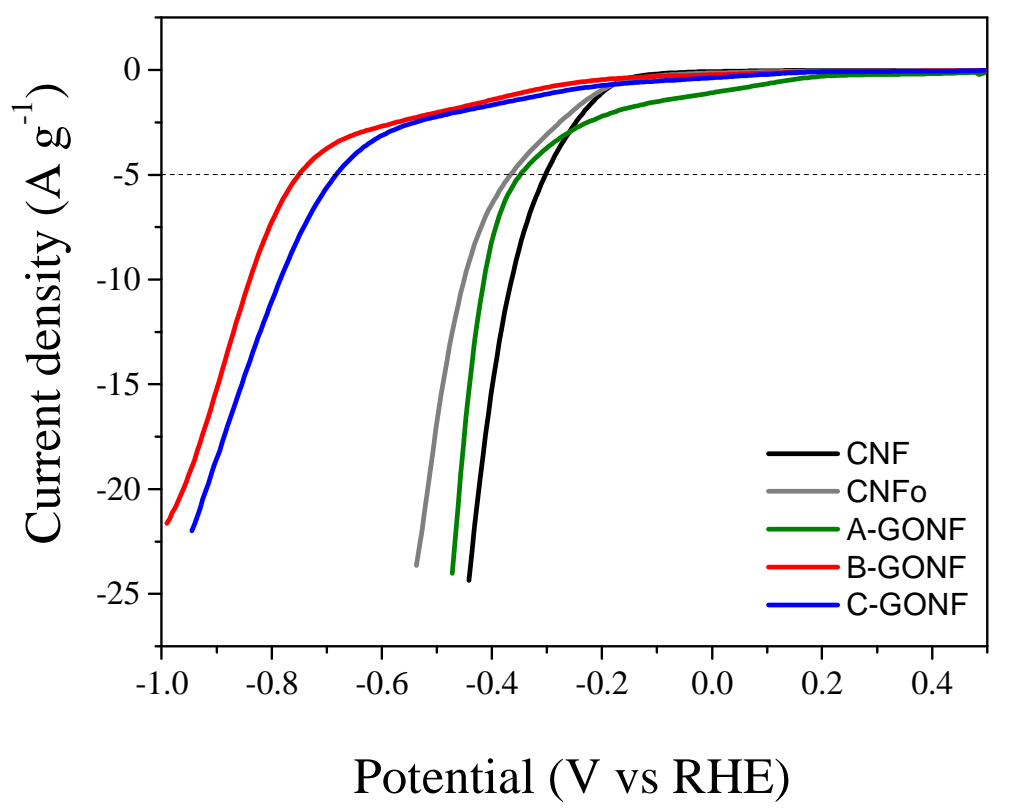

Figure 7. LSV from 0.5 to $1.0 \mathrm{~V}$ vs. RHE at $10 \mathrm{mV} \mathrm{s}^{-1}$ for $\mathrm{CNF}, \mathrm{CNF}$, and $\mathrm{A}, \mathrm{B}$ and $\mathrm{C}$ treated samples. Electrolyte: $0.5 \mathrm{M} \mathrm{H}_{2} \mathrm{SO}_{4}$.

Firstly, a different behaviour toward the HER was found depending on the nature of the carbon material. CNF and CNFo exhibited a sharp increase in the cathodic current density at potentials more negative than $-0.3 \mathrm{~V}$ vs. RHE. The latter is due to hydrogen formation by water reduction. However, GONF present another cathodic process previously to the sharp feature in the current-potential curve. This region (in the potential range from 0.2 to $-0.2 \mathrm{~V}$ for A-GONF and from -0.2 to $-0.6 \mathrm{~V}$ for B- and C-GONF) may be attributed to the reduction of oxygenated species in addition to HER. Spectro-electrochemical methods, such as differential electrochemical mass spectrometry should be used to determine if HER is taking place in this region $[35,58]$.

Comparing the performance of the materials at a current density of $5 \mathrm{~A} \mathrm{~g}^{-1}$, where only HER takes place for all the samples, CNF exhibited the most positive potential $(-0.30 \mathrm{~V})$, followed by A-GONF (-0.35 V) and CNFo $(-0.37 \mathrm{~V})$. These results show that despite the high content of oxygenated species introduced during the chemical oxidation and expansion, A-GONF still 
presents a strong formation of hydrogen. This activity is even better than that observed for the material treated with nitric acid (CNFo). The particular structure of A-GONF might provide this improved performance toward the HER. In this context, pristine CNF present nickel impurities (below 12 wt. \% [31]), which is an active metal for hydrogen evolution, and thus, the high formation of hydrogen at this surface may be attributed to the presence of Ni. After the treatment with nitric acid (CNFo) or chemical oxidation/exfoliation (A-GONF), metal impurities are removed from the carbon matrix and thus, the activity is mostly provided by carbon. Higher content of oxygen functional groups, which may decrease the density of active sites for HER, were determined for A-GONF in comparison to CNFo. However, LSW evidenced an enhanced behaviour for hydrogen evolution at the former material, which can be explained by its structure with the presence of both graphitic and graphene oxide domains. The graphene oxide domain provides more carbon defects (holes and edges), which are potentially active for electrochemical reactions.

In contrast, B- and C-GONF presented a poorer activity toward hydrogen evolution, with potentials at $5 \mathrm{~A} \mathrm{~g}^{-1}$ of -0.75 and $-0.68 \mathrm{~V}$ vs. RHE, respectively. The developed microporosity of these materials leads to a lower wettability by the electrolyte and hence, a higher surface available for electrochemical reactions. Additionally, the high extent of oxygenated species may result in the blockage of active sites. It has been reported that carbon-hydrogen bonds are more easily formed in carbon materials with a lower content of oxygen surface groups [61]. This aspect, together with the eventual influence of carbon defects [62], can be influencing the worse activity of the GONF oxidized under harsh conditions (B- and C-GONF). These results indicate strategies to either favor or hinder hydrogen evolution at practical electrodes.

\section{CONCLUSIONS}


Fishbone graphene oxide nanofibers were successfully obtained by chemical oxidation and subsequent ultrasound-assisted exfoliation of fishbone CNF. This novel material presents a filamentous morphology with an interlayer spacing between the graphene stacked cones that form the nanofiber similar to that found in graphene oxide materials. Various oxidation ratios $\left(\mathrm{OR}=\mathrm{KMnO}_{4} /\right.$ sample $=6.0$ and $\left.8.6 \mathrm{wt} . \%\right)$ and sonication times $(60$ and $120 \mathrm{~min})$ were used in order to study their impact on the formation of GONF and to obtain materials with different properties. The electrochemical capacitance of GONF was studied by cyclic voltammetry and IES in an acid electrolyte $\left(0.5 \mathrm{M} \mathrm{H}_{2} \mathrm{SO}_{4}\right)$. Materials were also tested for the hydrogen evolution reaction.

Synthesized GONF exhibited unique features due to the combination of the 1D morphology of the parent $\mathrm{CNF}$ with the presence of accessible graphene oxide sheets along its structure. Indeed, XPS analysis evidenced a noticeable increase in the surface oxygen amount with values around 17.9-20.5 wt.\% for GONF, while low oxygen contents were obtained for pristine CNF. Additionally, sulphur species were also intercalated in the GONF surface. $\mathrm{N}_{2}$ and $\mathrm{CO}_{2}$ physisorption showed that GONF structure provides a combination of micro- and mesoporous texture, which may be suitable for electrochemical applications.

Chemical oxidation and exfoliation led to an important rise in the electrochemical capacitance from 4 to 27 times depending on the oxidation conditions. The highest capacity $\left(49.2 \mathrm{~F} \mathrm{~g}^{-1}\right)$ was obtained when an OR of 6 was used under 60 min of sonication. This behaviour can be explained by the presence of both graphitic and graphene oxide domains. In this context, most severe oxidation conditions resulted in a progressive partial loss of the graphitic domain and a more developed microporosity and lower capacitance values were obtained. Moreover, the optimized material presented also the best performance for hydrogen evolution in the base electrolyte. 
The proposed strategy represents a scalable and high-yield approach for the production of graphene materials with tuneable properties using graphite as starting material. The synthesized GONF present unique features, which makes them promising candidates for catalytic, composite materials and energy applications. Additionally, physicochemical and electrochemical features can be easily tuneable, controlling the oxidation degree, i.e. varying the oxidation ratio or the sonication time.

\section{Acknowledgments}

This work was funded by FEDER, the Spanish Ministry of Science, Innovation and Universities MICINN (ENE2017-83976-C2-1-R \& ENE2017-83854-R) and by the Aragón Government to the Fuel Conversion Group (T06_17R). DS thanks MICINN for his Ramon y Cajal research contract (RyC-2016-20944). The microscopy works have been conducted in the "Laboratorio de Microscopías Avanzadas" at "Instituto de Nanociencia de Aragón Universidad de Zaragoza”. Authors acknowledge the LMA-INA for offering access to their instruments and expertise.

\section{References}

[1] L.V. Radushkevich, V.M. Lukyanovich, O strukture ugleroda, obrazujucegosja pri termiceskom razlozenii okisi ugleroda na zeleznom kontakt, Zurn Fisic. Chim., 26 (1952) 8895.

[2] J. Vera-Agullo, H. Varela-Rizo, J.A. Conesa, C. Almansa, C. Merino, I. Martin-Gullon, Evidence for growth mechanism and helix-spiral cone structure of stacked-cup carbon nanofibers, Carbon, 45 (2007) 2751-2758. 
[3] I. Martin-Gullon, J. Vera, J.A. Conesa, J.L. González, C. Merino, Differences between carbon nanofibers produced using $\mathrm{Fe}$ and $\mathrm{Ni}$ catalysts in a floating catalyst reactor, Carbon, 44 (2006) 1572-1580.

[4] P. Serp, M. Corrias, P. Kalck, Carbon nanotubes and nanofibers in catalysis, Appl. Catal., A, 253 (2003) 337-358.

[5] K.P. De Jong, J.W. Geus, Carbon Nanofibers: Catalytic Synthesis and Applications, Catal. Rev. Sci. Eng., 42 (2000) 481-510.

[6] J. Huang, Y. Liu, T. You, Carbon nanofiber based electrochemical biosensors: A review, Analytical Methods, 2 (2010) 202-211.

[7] S. Pérez-Rodríguez, D. Torres, M.J. Lázaro, Effect of oxygen and structural properties on the electrical conductivity of powders of nanostructured carbon materials, Powder Technol., 340 (2018) 380-388.

[8] M.E. Gálvez, L. Calvillo, C. Alegre, D. Sebastián, I. Suelves, S. Pérez-Rodríguez, V. Celorrio, E. Pastor, J.I. Pardo, R. Moliner, M.J. Lázaro, Nanostructured carbon materials as supports in the preparation of direct methanol fuel cell electrocatalysts, Catalysts, 3 (2013) 671-682.

[9] R. Rizo, D. Sebastián, J.L. Rodríguez, M.J. Lázaro, E. Pastor, Influence of the nature of the carbon support on the activity of $\mathrm{Pt} / \mathrm{C}$ catalysts for ethanol and carbon monoxide oxidation, J. Catal., 348 (2017) 22-28.

[10] C.A. Bessel, K. Laubernds, N.M. Rodriguez, R.T.K. Baker, Graphite Nanofibers as an Electrode for Fuel Cell Applications, J. Phys. Chem. B, 105 (2001) 1115-1118.

[11] D. Sebastián, I. Suelves, R. Moliner, M.J. Lázaro, A. Stassi, V. Baglio, A.S. Aricò, Optimizing the synthesis of carbon nanofiber based electrocatalysts for fuel cells, Appl. Catal., B, 132-133 (2013) 22-27. 
[12] A.G. Pandolfo, A.F. Hollenkamp, Carbon properties and their role in supercapacitors, J. Power Sources, 157 (2006) 11-27.

[13] E.S. Pampal, E. Stojanovska, B. Simon, A. Kilic, A review of nanofibrous structures in lithium ion batteries, J. Power Sources, 300 (2015) 199-215.

[14] A. Ambrosi, C.K. Chua, A. Bonanni, M. Pumera, Electrochemistry of Graphene and Related Materials, Chem. Rev. (Washington, DC, U. S.), 114 (2014) 7150-7188.

[15] D. Torres, D. Sebastián, M.J. Lázaro, J.L. Pinilla, I. Suelves, A.S. Aricò, V. Baglio, Performance and stability of counter electrodes based on reduced few-layer graphene oxide sheets and reduced graphene oxide quantum dots for dye-sensitized solar cells, Electrochim. Acta, 306 (2019) 396-406.

[16] R. Rizo, S. Pérez-Rodríguez, G. García, Well-Defined Platinum Surfaces for the Ethanol Oxidation Reaction, ChemElectroChem, 0 (2019).

[17] C. Hou, M. Zhang, A. Halder, Q. Chi, Graphene directed architecture of fine engineered nanostructures with electrochemical applications, Electrochim. Acta, 242 (2017) 202-218. [18] J.C. Charlier, J.P. Issi, Electrical conductivity of novel forms of carbon, Journal of Physics and Chemistry of Solids, 57 (1996) 957-965.

[19] K. Balasubramanian, M. Burghard, Chemically Functionalized Carbon Nanotubes, Small, 1 (2005) 180-192.

[20] T. Kuila, S. Bose, A.K. Mishra, P. Khanra, N.H. Kim, J.H. Lee, Chemical functionalization of graphene and its applications, Progress in Materials Science, 57 (2012) 1061-1105.

[21] M.L. Toebes, J.M.P. van Heeswijk, J.H. Bitter, A. Jos van Dillen, K.P. de Jong, The influence of oxidation on the texture and the number of oxygen-containing surface groups of carbon nanofibers, Carbon, 42 (2004) 307-315. 
[22] D. Sebastián, I. Suelves, R. Moliner, M.J. Lázaro, The effect of the functionalization of carbon nanofibers on their electronic conductivity, Carbon, 48 (2010) 4421-4431.

[23] L. Calvillo, M.J. Lázaro, I. Suelves, Y. Echegoyen, E.G. Bordejé, R. Moliner, Study of the Surface Chemistry of Modified Carbon Nanofibers by Oxidation Treatments in Liquid Phase, J. Nanosci. Nanotechnol., 9 (2009) 4164-4169.

[24] W.S. Hummers, R.E. Offeman, Preparation of graphitic oxide, J. Am. Chem. Soc., 80 (1958) 1339-1339.

[25] A. Lerf, H. He, M. Forster, J. Klinowski, Structure of Graphite Oxide Revisitedl, J. Phys. Chem. B, 102 (1998) 4477-4482.

[26] T. Szabó, O. Berkesi, P. Forgó, K. Josepovits, Y. Sanakis, D. Petridis, I. Dékány, Evolution of Surface Functional Groups in a Series of Progressively Oxidized Graphite Oxides, Chem. Mater., 18 (2006) 2740-2749.

[27] S. Eigler, C. Dotzer, F. Hof, W. Bauer, A. Hirsch, Sulfur Species in Graphene Oxide, Chemistry - A European Journal, 19 (2013) 9490-9496.

[28] P. Feicht, D.A. Kunz, A. Lerf, J. Breu, Facile and scalable one-step production of organically modified graphene oxide by a two-phase extraction, Carbon, 80 (2014) 229-234. [29] W. Kiciński, M. Szala, M. Bystrzejewski, Sulfur-doped porous carbons: Synthesis and applications, Carbon, 68 (2014) 1-32.

[30] J.K. Chinthaginjala, K. Seshan, L. Lefferts, Preparation and Application of CarbonNanofiber Based Microstructured Materials as Catalyst Supports, Ind. Eng. Chem. Res., 46 (2007) 3968-3978.

[31] D. Torres, J.L. Pinilla, E.M. Galvez, I. Suelves, Graphene quantum dots from fishbone carbon nanofibers, RSC Adv., 6 (2016) 48504-48514. 
[32] C. Botas, A.M. Pérez-Mas, P. Álvarez, R. Santamaría, M. Granda, C. Blanco, R.

Menéndez, Optimization of the size and yield of graphene oxide sheets in the exfoliation step, Carbon, 63 (2013) 576-578.

[33] R. Rasuli, A. Iraji zad, Density functional theory prediction for oxidation and exfoliation of graphite to graphene, Appl. Surf. Sci., 256 (2010) 7596-7599.

[34] R.J.W.E. Lahaye, H.K. Jeong, C.Y. Park, Y.H. Lee, Density functional theory study of graphite oxide for different oxidation levels, Phys. Rev. B: Condens. Matter., 79 (2009).

[35] S. Pérez-Rodríguez, D. Sebastián, M.J. Lázaro, E. Pastor, Stability and catalytic properties of nanostructured carbons in electrochemical environments, J. Catal., 355 (2017) 156-166.

[36] J.L. Pinilla, R. Utrilla, M.J. Lázaro, I. Suelves, R. Moliner, J.M. Palacios, A novel rotary reactor configuration for simultaneous production of hydrogen and carbon nanofibers, Int. J. Hydrogen Energy, 34 (2009) 8016-8022.

[37] S. de Llobet, J.L. Pinilla, M.J. Lázaro, R. Moliner, I. Suelves, Catalytic decomposition of biogas to produce H2-rich fuel gas and carbon nanofibers. Parametric study and characterization, Int. J. Hydrogen Energy, 37 (2012) 7067-7076.

[38] J.L. Pinilla, D. Torres, M.J. Lázaro, I. Suelves, R. Moliner, I. Cañadas, J. Rodríguez, A. Vidal, D. Martínez, Metallic and carbonaceous -based catalysts performance in the solar catalytic decomposition of methane for hydrogen and carbon production, Int. J. Hydrogen Energy, 37 (2012) 9645-9655.

[39] S. Park, R.S. Ruoff, Chemical methods for the production of graphenes, Nat. Nanotechnol., 4 (2009) 217-224.

[40] S. Stankovich, R.D. Piner, X. Chen, N. Wu, S.T. Nguyen, R.S. Ruoff, Stable aqueous dispersions of graphitic nanoplatelets via the reduction of exfoliated graphite oxide in the presence of poly(sodium 4-styrenesulfonate), J. Mater. Chem., 16 (2006) 155-158. 
[41] S. Gilje, S. Han, M. Wang, K.L. Wang, R.B. Kaner, A Chemical Route to Graphene for Device Applications, Nano Lett., 7 (2007) 3394-3398.

[42] D. Torres, J.L. Pinilla, R. Moliner, I. Suelves, On the oxidation degree of few-layer graphene oxide sheets obtained from chemically oxidized multiwall carbon nanotubes, Carbon, 81 (2015) 405-417.

[43] J. Biscoe, An x-ray study of carbon black, J. Appl. Phys., 13 (1942) 364-371.

[44] C. Botas, P. Álvarez, C. Blanco, R. Santamaría, M. Granda, M.D. Gutiérrez, F. Rodríguez-Reinoso, R. Menéndez, Critical temperatures in the synthesis of graphene-like materials by thermal exfoliation-reduction of graphite oxide, Carbon, 52 (2013) 476-485. [45] S. Pei, H.M. Cheng, The reduction of graphene oxide, Carbon, 50 (2012) 3210-3228. [46] H. Estrade-Szwarckopf, XPS photoemission in carbonaceous materials: A "defect" peak beside the graphitic asymmetric peak, Carbon, 42 (2004) 1713-1721.

[47] B. Garg, T. Bisht, Y.C. Ling, Graphene-based nanomaterials as heterogeneous acid catalysts: A comprehensive perspective, Molecules, 19 (2014) 14582-14614.

[48] M. Thommes, K. Kaneko, V. Neimark Alexander, P. Olivier James, F. RodriguezReinoso, J. Rouquerol, S.W. Sing Kenneth, Physisorption of gases, with special reference to the evaluation of surface area and pore size distribution (IUPAC Technical Report), Pure Appl. Chem., 87 (2015) 1051-1069.

[49] X. Zhao, Q. Zhang, C.-M. Chen, B. Zhang, S. Reiche, A. Wang, T. Zhang, R. Schlögl, D. Sheng Su, Aromatic sulfide, sulfoxide, and sulfone mediated mesoporous carbon monolith for use in supercapacitor, Nano Energy, 1 (2012) 624-630.

[50] M. Seredych, T.J. Bandosz, S-doped micro/mesoporous carbon-graphene composites as efficient supercapacitors in alkaline media, Journal of Materials Chemistry A, 1 (2013) 11717-11727. 
[51] M.J. Bleda-Martínez, J.A. Maciá-Agulló, D. Lozano-Castelló, E. Morallón, D. CazorlaAmorós, A. Linares-Solano, Role of surface chemistry on electric double layer capacitance of carbon materials, Carbon, 43 (2005) 2677-2684.

[52] M.J. Bleda-Martínez, D. Lozano-Castelló, E. Morallón, D. Cazorla-Amorós, A. LinaresSolano, Chemical and electrochemical characterization of porous carbon materials, Carbon, 44 (2006) 2642-2651.

[53] R. Zhang, X. Jing, Y. Chu, L. Wang, W. Kang, D. Wei, H. Li, S. Xiong, Nitrogen/oxygen co-doped monolithic carbon electrodes derived from melamine foam for high-performance supercapacitors, Journal of Materials Chemistry A, 6 (2018) 17730-17739. [54] W.H. Choi, M.J. Choi, J.H. Bang, Nitrogen-Doped Carbon Nanocoil Array Integrated on Carbon Nanofiber Paper for Supercapacitor Electrodes, ACS Appl. Mater. Interfaces, 7 (2015) 19370-19381.

[55] F. Lufrano, P. Staiti, M. Minutoli, Evaluation of nafion based double layer capacitors by electrochemical impedance spectroscopy, J. Power Sources, 124 (2003) 314-320.

[56] D. Qu, H. Shi, Studies of activated carbons used in double-layer capacitors, J. Power Sources, 74 (1998) 99-107.

[57] J. Gamby, P.L. Taberna, P. Simon, J.F. Fauvarque, M. Chesneau, Studies and characterisations of various activated carbons used for carbon/carbon supercapacitors, J. Power Sources, 101 (2001) 109-116.

[58] S. Pérez-Rodríguez, G. García, M.J. Lázaro, E. Pastor, DEMS strategy for the determination of the difference in surface acidity of carbon materials, Electrochem. Commun., 90 (2018) 87-90.

[59] S. Pérez-Rodríguez, E. Pastor, M.J. Lázaro, Electrochemical behavior of the carbon black Vulcan XC-72R: Influence of the surface chemistry, Int. J. Hydrogen Energy, 43 (2018) 7911-7922. 
[60] K. Jurewicz, E. Frackowiak, F. Béguin, Towards the mechanism of electrochemical hydrogen storage in nanostructured carbon materials, Applied Physics A, 78 (2004) 981-987. [61] S. Leyva-García, E. Morallón, D. Cazorla-Amorós, F. Béguin, D. Lozano-Castelló, New insights on electrochemical hydrogen storage in nanoporous carbons by in situ Raman spectroscopy, Carbon, 69 (2014) 401-408.

[62] M.J. Bleda-Martínez, J.M. Pérez, A. Linares-Solano, E. Morallón, D. Cazorla-Amorós, Effect of surface chemistry on electrochemical storage of hydrogen in porous carbon materials, Carbon, 46 (2008) 1053-1059. 